RASĀYAN J. Chem.

Vol. 13 | No. 1 |488 - 493| January - March | 2020 ISSN: 0974-1496 | e-ISSN: 0976-0083 | CODEN: RJCABP http://www.rasayanjournal.com http://www.rasayanjournal.co.in

\title{
NOVEL HETEROPOLYACID SALT: TITANIUM (IV) MOLYBDOTUNGSTATE
}

\author{
N. Sharma ${ }^{1, *}$, H.K. Sharma ${ }^{2}$ and P. Dogra ${ }^{1}$ \\ ${ }^{1}$ Department of Chemistry, MMDU, Mullana, Ambala-133207, Haryana, INDIA* \\ ${ }^{2}$ MM University, Sadopur, Ambala-134007, Haryana, INDIA \\ *E-mail:sameeksha20002@gmail.com
}

\begin{abstract}
The present investigation describes the geometry of an original compound, Titanium (IV) molybdotungstate [TiMoW] prepared by using the ion-exchange route. To elaborate the structural aspects various analytical techniques were employed. The amorphous behavior of the compound was established using XRD. Infrared spectroscopy was used to assign dynamic sites responsible for acidic characteristics of the sample. SEM/EDS has been used to describe the composition of elements present in the prepared sample. Thermogravimetric techniques indicated the weight loss rate and helped in ascertaining the number of water molecules. Thereafter, the derived structure furnished a geometry of heteropolyacid salt, embedded with acidic and ion exchange characteristics.
\end{abstract}

Keywords: Titanium Molybdotungstate, Synthesis, Heteropolyacid, Ion-exchange, IR.

(C) RASĀYAN. All rights reserved

\section{INTRODUCTION}

Heteropolyacid salts act as promising ion exchangers for the detection and estimation of metal ions and also as efficient catalysts for organic synthesis. Besides these major applications, these complex compounds can be used in analysis, histology and also as a dynamic component of many reagents like Folin-Ciocalteu reagent and folins phenol etc. Keggin has formulated the structural aspects of $\alpha$ Keggin anions using an X-ray diffraction pattern. ${ }^{1}$ Later on, M.T. Pope extended the structural aspects of these compounds and suggested that the fundamental unit comprises of setting up of $\mathrm{MO}_{6}$ octahedral having fragments of metal oxide structures. ${ }^{2} \mathrm{~W}$ Grace ${ }^{3}$ synthesized titanium arsenate which is selective for a number of ions such as $\mathrm{Ba}^{2+}, \mathrm{Sr}^{2+}, \mathrm{Cd}^{2+}, \mathrm{Zn}^{2+}, \mathrm{Cu}^{2+}, \mathrm{Pb}^{2+}$. Qureshi and his co-workers synthesized a series of titanium-based isopolyacid salts; titanium tungstate, titanium molybdenite, titanium antimonite which are used to separate the alkali metal ions and titanium selenite was used as $\mathrm{Cd}^{2+}$ selective ion exchanger..$^{4-7}$ Titanium vanadate synthesized at various $\mathrm{pH}(10,6.8,4.8$, and 2.7$)$ and exchanger having $0.65 \mathrm{meq} / \mathrm{g}$ ion-exchange capacity was used for binary mixtures separation of $\mathrm{Sr}^{+2}$ with $\mathrm{Ba}^{2+}, \mathrm{Ca}^{2+}$ and $\mathrm{Mg}^{+2}$ while titanium silicate was used for the separation of transition metal ions. ${ }^{8-9} \mathrm{~L}$. Szirtes and $\mathrm{L}$. Zsinka prepared amorphous titanium tellurate. ${ }^{10}$ Sharma et al studied the chromatographic behavior of 40 metal ions using titanium-based ion exchanger. ${ }^{11}$ This property can be useful for the estimation of environmentally hazardous ${ }^{12}$ ions. Most of these salts were selective for more than one metal ion and were employed for chromatographic separation of generally binary mixtures. Thus, their use as a sensor cannot give the utmost consistency, which is the vital requirement for the estimation of any metal ion and then an era of double salts of heteropolyacids came into limelight and frequent augmentation was observed in this field. This field has provided a zenith for researchers. The crystalline phase of titanium (IV) tungstosilicate having $0.44 \mathrm{meq} / \mathrm{g}$ IEC was prepared by Siddiqi and Pathania by adding solutions of tungstosilicic acid with alcoholic solution of titanium (IV) chloride and then employed for the separation of ions using column operation methodology. ${ }^{13}$ Titanium arsenosilicate was prepared by Varshney et al. ${ }^{14}$ Ahmad et al synthesized Titanium tungstophosphate immobilized on silica and employed it for the removal of lanthanum. ${ }^{15}$ Yaveri et al synthesized and studied analytical application of Titanium (IV) molybdophosphate. ${ }^{16}$ A lead selective exchanger named Titanium aluminum silicate was assembled by

Rasayan J. Chem., 13(1), 488-493(2020)

http://dx.doi.org/10.31788/RJC.2020.1315355

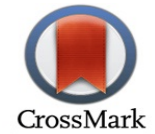


RASĀYAN J. Chem.

Vol. 13 | No. 1 | 488 - 493| January - March | 2020

Sun et al. ${ }^{17}$ Kuznicki et al synthesized amorphous heteropolyacid salt named titanium phosphosilicate. ${ }^{18}$

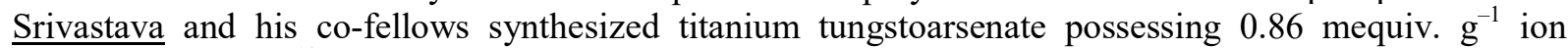
exchange capacity. ${ }^{19}$ Recently, a composite membrane based on sulfonated polysulfone-natural zeolitetitanium dioxide has been prepared..$^{20}$ Most of the above-mentioned reports contain molybdate, titanates and tungstate in the separate heteropoly compounds, but we have incorporated successfully all the three moieties in a single complex showing heteropoly compound characteristics and some of our successful efforts in this field are shown in references. ${ }^{21-25}$ The work presented in this manuscript depicts the synthesis and characterization of a novel compound named TiMoW.

\section{EXPERIMENTAL}

Material and Methods

Essential metal ion solutions were prepared by weighing reagents of utmost purity i.e. greater than $99 \%$. Standardization was carried out, wherever required. IR studies of TiMoW were carried out with an instrument having specification as "Perkin, ABB spectrophotometer" (resolution $>0.7 \mathrm{~cm}^{-1}$ ) by impregnating in $\mathrm{KBr}$ pellet. X-ray powder analysis of the compound was done with Rigaku Dmax III C instrument. TGA analysis was done on Mettler Toledo Star System with a limited deviation of $\pm 0.25 \mathrm{~K}$ and the temperature precision is up to $\pm 0.15 \mathrm{~K}$. SEM/EDS of synthesized material was performed with JEOL (JSM 6510LV) instrument.

\section{Preparation of Titanium [IV] Molybdotungstate [TiMoW]}

Different samples of TiMoW were prepared by slow addition of titanium (IV) chloride solution to a constantly stirred aqueous solution of sodium molybdate and sodium tungstate (high purity, procured from $\mathrm{CDH}$ chemicals/Merck chemicals) under variable conditions as mentioned in the table 1. Sticky silvery light precipitates were obtained, which were digested for 3 hours to get pure and superior quality exchanger. Then, the precipitates were separated from an excess of chloride ion by frequently washing with DDW and then again dried at $40^{\circ} \mathrm{C}$. Subsequently, the material was converted to granular form by immersing in DDW. The material was transformed into active species i.e. $\mathrm{H}^{+}$form. The activated form was excessively washed with water to get rid of the excess of sticky acid and finally, the samples were again dried at low temperature i.e. $40^{\circ} \mathrm{C}$. Different preparatory conditions (given in Table-1) were tried and sample no. 1 was picked up for further investigations, as this is comparatively better ion exchanger because of maximum IEC.

\section{Physicochemical Characterization \\ Ion Exchange Capacity (IEC)}

To determine IEC of the sample, column operation methodology was employed as mentioned in the previous communications. ${ }^{21-25}$

\section{Distribution Coefficient Studies (Kd)}

Distribution coefficients $(\mathrm{Kd})$ for various metal ions were calculated by following the same strategy and formula as described in previous reports. ${ }^{21-25}$ Results are summarized in Table-2.

\section{Structural Characterization \\ Infrared Spectra}

Metal-oxygen linkages exhibit a variety of characteristic vibrational bands to elucidate polyoxometalate chemistry.

- internal oxygen connecting X-M,

- edge-sharing oxygen connecting M's,

- corner-sharing oxygen connecting $\mathrm{M}_{3} \mathrm{O}_{13}$ units and

- terminal metal-oxygen bonding.

FTIR spectra in the region $1200-600 \mathrm{~cm}^{-1}$ explain M-O bonding pattern in the heteropoly compounds $\mathrm{s}^{26,27}$ and FTIR findings of the compound are plotted in Fig.-1. 
RASĀYAN J. Chem.

Vol. 13 | No. 1 |488 - 493| January - March | 2020

Table-1: Optimization of Preparatory Conditions of TiMoW.

\begin{tabular}{|c|c|c|c|c|c|c|}
\hline $\begin{array}{c}\text { Sample } \\
\text { No. }\end{array}$ & Respective Ingredients & $\begin{array}{l}\text { Volume } \\
\text { Ratio }\end{array}$ & $\begin{array}{c}\text { Molar } \\
\text { Concentration }\end{array}$ & $\begin{array}{l}\text { Temp } \\
\left({ }^{0} \mathrm{C}\right)\end{array}$ & $\mathrm{pH}$ & $\begin{array}{c}\text { IEC } \\
(\mathrm{meq} / \mathrm{g})\end{array}$ \\
\hline \multirow[t]{3}{*}{1.} & $\mathrm{TiCl}_{4}$ & 2 & 1 & \multirow[t]{3}{*}{60} & \multirow[t]{3}{*}{1.0} & \multirow[t]{3}{*}{0.982} \\
\hline & $\mathrm{Na}_{2} \mathrm{WO}_{4}$ & 1 & 1 & & & \\
\hline & $\mathrm{Na}_{2} \mathrm{MoO}_{4}$ & 1 & 1 & & & \\
\hline \multirow[t]{3}{*}{2.} & $\mathrm{TiCl}_{4}$ & 2 & 2 & \multirow[t]{3}{*}{55} & \multirow[t]{3}{*}{1.8} & \multirow[t]{3}{*}{0.664} \\
\hline & $\mathrm{Na}_{2} \mathrm{WO}_{4}$ & 1 & 1 & & & \\
\hline & $\mathrm{Na}_{2} \mathrm{MoO}_{4}$ & 1 & 1 & & & \\
\hline \multirow[t]{3}{*}{3.} & $\mathrm{TiCl}_{4}$ & 1.5 & 1 & \multirow[t]{3}{*}{60} & \multirow[t]{3}{*}{1.6} & \multirow[t]{3}{*}{0.845} \\
\hline & $\mathrm{Na}_{2} \mathrm{WO}_{4}$ & 1 & 1 & & & \\
\hline & $\mathrm{Na}_{2} \mathrm{MoO}_{4}$ & 1 & 1 & & & \\
\hline \multirow[t]{3}{*}{4.} & $\mathrm{TiCl}_{4}$ & 2 & 2 & \multirow[t]{3}{*}{65} & \multirow[t]{3}{*}{1.2} & \multirow[t]{3}{*}{0.878} \\
\hline & $\mathrm{Na}_{2} \mathrm{WO}_{4}$ & 1 & 1 & & & \\
\hline & $\mathrm{Na}_{2} \mathrm{MoO}_{4}$ & 1 & 1 & & & \\
\hline \multirow[t]{3}{*}{5.} & $\mathrm{TiCl}_{4}$ & 1 & 1 & \multirow[t]{3}{*}{60} & \multirow[t]{3}{*}{1.2} & \multirow[t]{3}{*}{0.975} \\
\hline & $\mathrm{Na}_{2} \mathrm{WO}_{4}$ & 1 & 1 & & & \\
\hline & $\mathrm{Na}_{2} \mathrm{MoO}_{4}$ & 1 & 1 & & & \\
\hline
\end{tabular}

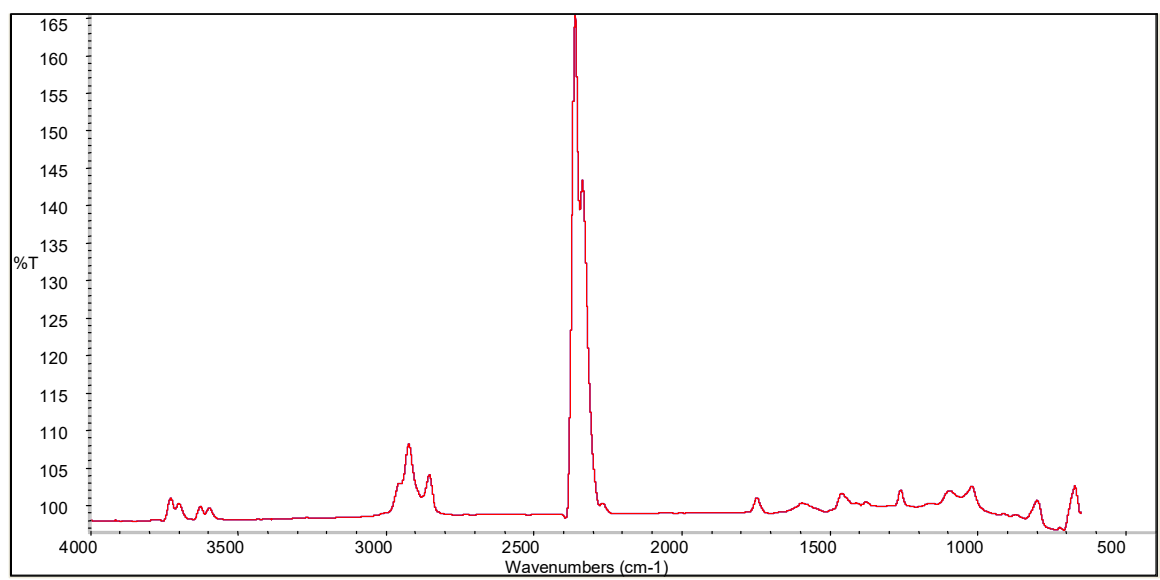

Fig.-1: FTIR Spectrum of TiMoW

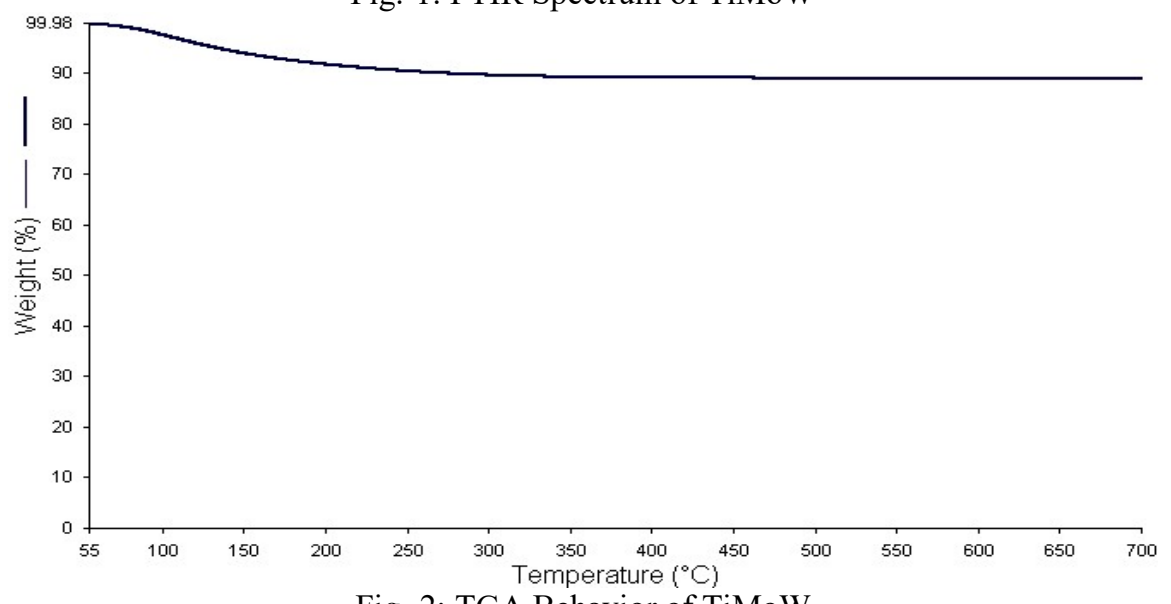

Fig.-2: TGA Behavior of TiMoW

Table-2: $\mathrm{K}_{\mathrm{d}}$ Values for Various Metal Ions

\begin{tabular}{c|c|c|c|c|c|c|c|c|c}
\hline $\begin{array}{c}\text { Rare Earth Metal } \\
\text { Ion }\end{array}$ & Gd(III) & Pr(III) & Er(III) & Sm(III) & La(III) & Ce(III) & Eu(III) & Tb(III) & Y(III) \\
\hline $\mathrm{K}_{\mathrm{d}}$ & 16.7 & 17.7 & 22.6 & 8.0 & 8.9 & 33.5 & 14.0 & 9.0 & 37.8 \\
\hline
\end{tabular}


RASĀYAN J. Chem.

Vol. 13 | No. 1 |488 - 493| January - March | 2020

5

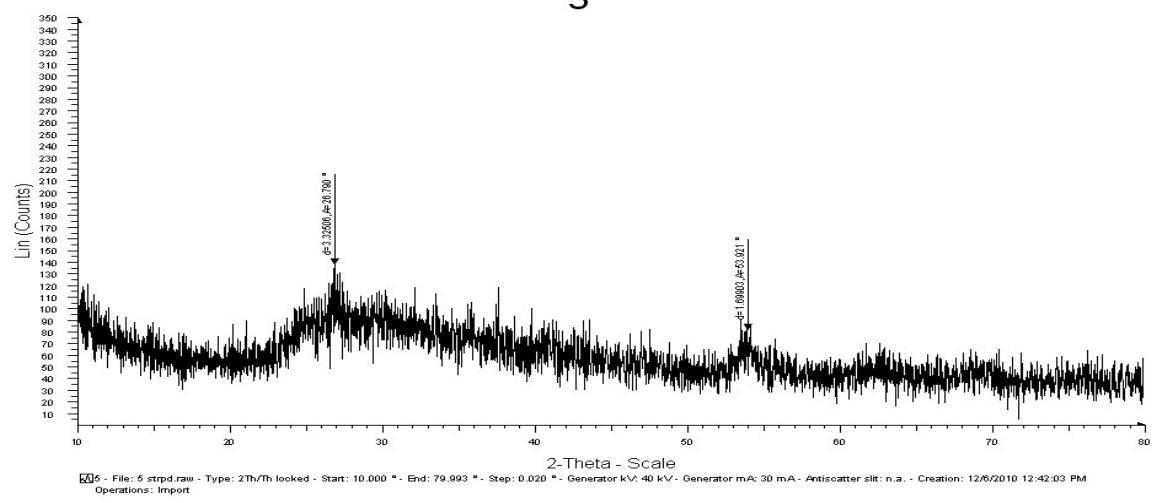

Fig.-3: X-ray Diffraction Pattern

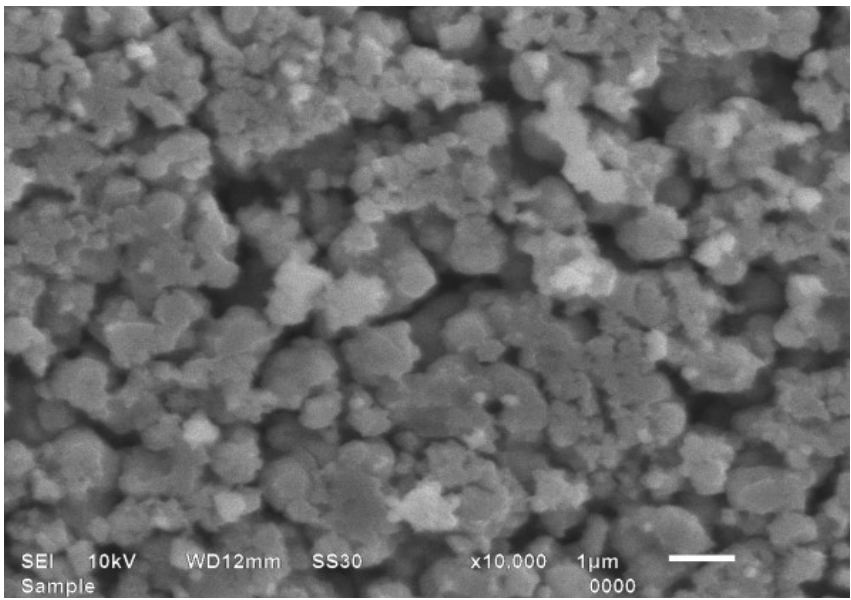

Fig.-4: SEM Image

Thermal Analysis

A TGA curve of the sample is symbolized in Fig.-2.

\section{X-Ray Diffraction}

The resultant pattern of XRD analysis of TiMoW is shown in Fig.-3.

Scanning Electron Microscopy and Energy Dispersive Spectroscopy [SEM and EDS]

SEM images of the prepared compound are shown in Fig.-4.

\section{Ion-exchange Capacity}

\section{RESULTS AND DISCUSSION}

Out of various samples synthesized under different conditions, IEC of the superior sample (1) was deduced as $0.98 \pm 0.02 \mathrm{meq}^{-1}$. Sample 1 is highly selective for $\mathrm{Y}(\mathrm{III})$, as it is evident from $\mathrm{Kd}$ values.

\section{Instrumental Characterization}

Results of FTIR of TiMoW confirmed different bands present in the compound corresponding to heteropoly compounds.

The broad peak at $3625 \mathrm{~cm}^{-1}$, weak band at $2921 \mathrm{~cm}^{-1}$, sharp band at 1740 corresponds to various stretching and bending modes of the interstitial water molecule, whereas sharp band at $1393 \mathrm{~cm}^{-1}$ and broadband at 985-675 $\mathrm{cm}^{-1}$ represents stretching and bending mode of metal-oxygen bonds.

Coupling of electronic states and vibration of the molecules broadened or moved the bands from their normal modes. 


\section{RASĀYAN J. Chem.}

Vol. 13 | No. 1 |488 - 493| January - March | 2020

Electron diffraction spectra of TiMoW shows the atomic ratio of various elements in the compound Ti:Mo:W:O::19.64:18.75:27.10:34.52, respectively. Thus, various calculations give the empirical formula of the synthesized exchanger as $\left[\left(\mathrm{TiO}_{2}\right)_{1.047}\left(\mathrm{H}_{3} \mathrm{MoO}_{3}\right)\left(\mathrm{H}_{3} \mathrm{WO}_{4}\right)_{1.445}\right] . \mathrm{nH}_{2} \mathrm{O}$

Thermal Analysis indicated that TiMoW loses $8.5 \%$ of weight up to a temperature of $200^{\circ} \mathrm{C}$. This weight loss pattern assisted in the estimation of number of water molecules ' $n$ ' by using Alberti formula: ${ }^{28}$

$$
18 \mathrm{n}=\mathrm{X}(\mathrm{M}+18 \mathrm{n}) / 100
$$

This gives the value of ' $\mathrm{n}$ ' as $2.959 \approx 3$. Empirical formula of the exchanger can be written as $\left[\left(\mathrm{TiO}_{2}\right)_{1.047}\left(\mathrm{H}_{3} \mathrm{MoO}_{3}\right)\left(\mathrm{H}_{3} \mathrm{WO}_{4}\right)_{1.445}\right] .3 \mathrm{H}_{2} \mathrm{O}$ with a molecular weight 627.349 .

As the coordinated water molecule gets escaped and also there is a rearrangement of functional groups so further weight loss of $5.52 \%$ was observed up to $500^{\circ} \mathrm{C}$.

X-ray powder pattern of TiMoW is shown in Fig.-3 and the studies revealed that there was no definite angle of diffraction to tell about crystalline behavior, therefore, the amorphous nature of the compound is confirmed.

SEM images (Fig.-4) of titanium (IV) molybdotungstate explained that the particles are broad, having uneven contour, lacking crystallinity and clarity. These observations strongly favor amorphous nature with a linearly layered structure with little irregularity.

The present investigation depicts the complete structural information of this amorphous compound having empirical formula $\left[\left(\mathrm{TiO}_{2}\right)_{1.047}\left(\mathrm{H}_{3} \mathrm{MoO}_{3}\right)\left(\mathrm{H}_{3} \mathrm{WO}_{4}\right)_{1.445}\right] .3 \mathrm{H}_{2} \mathrm{O}$ with a molecular weight 627.349.

\section{Applications as Ion-selective Electrode}

On the basis of distribution coefficient values, it was conferred that Titanium (IV) molybdotungstate exhibited excellent selectivity towards Y(III) ions over other metal ions employed in the analysis. Thus, the prepared material can act as an effective electro-active component in the preparation of a sensor membrane and electrode sensitive for Y(III) ions.

\section{CONCLUSION}

A novel Heteropolyacid salt: titanium [IV] molybdotungstate has been synthesized under different reaction conditions and then structural analysis was done using different analytical and instrumental techniques. This analysis helps in formulation of empirical formula of the derived amorphous TiMoW product is $\left[\left(\mathrm{TiO}_{2}\right)_{1.047}\left(\mathrm{H}_{3} \mathrm{MoO}_{3}\right)\left(\mathrm{H}_{3} \mathrm{WO}_{4}\right)_{1.445}\right] .3 \mathrm{H}_{2} \mathrm{O}$ with a molecular weight 627.349 a.m.u. Thus, TiMoW has been identified as polyoxometallates selective for $\mathrm{Y}(\mathrm{III})$ species.

\section{ACKNOWLEDGMENT}

Authors are grateful to the MMDU, Mullana (Ambala) for providing various facilities for carrying out these studies.

\section{REFERENCES}

1. J.F. Keggins, Proceedings of the Royal Society A, 144, 75(1934), DOI: 10.1098/rspa.1934.0035.

2. M.T. Pope, Heteropoly and Isopoly Oxometalates, Verlag, Berlin (1983), DOI:10.1007/978-3-66212004-0.

3. W. Grace and Co., British Patent, 1, 181089(1970).

4. M. Qureshi and J.P. Gupta, Journal of Chemical Society A, 0, 1755(1969), DOI:10.1039/J19690001755

5. M. Qureshi and H.S. Rathore, Journal of Chemical Society A, 0 2515(1969), DOI: $10.1039 / \mathrm{J} 19690002515$

6. M. Qureshi and V. Kumar, Journal of Chemical Society A, 0, 1488(1970), DOI: $10.1039 / \mathrm{J} 19700001488$

7. M. Qureshi, R. Kumar and H.S. Rathore, Analytical Chemistry, 44, 1081(1972), DOI: $10.1021 / \mathrm{ac} 60314 \mathrm{a} 044$

8. M. Qureshi, K.G. Varshney and S.K. Kabiruddin, Canadian Journal of Chemistry, 50, 2071(1972), DOI: $10.1139 / \mathrm{v} 72-333$

9. C. Heitner, Wirguin and Albu-Yaron A. Belg, Patent, 10, 668(1965). 
RASĀYAN $J$. Chem.

Vol. 13 | No. 1 |488 - 493| January - March | 2020

10. L. Szirtes and L. Zsinka, Journal of Chromatography A, 102, 105(1974), DOI:10.1016/S00219673(01)85434-0

11. S.D. Sharma and R. Gupta, Journal of Chromatographic Science, 38(2), 61(2000), DOI: 10.1093/chromsci/38.2.61

12. S.K. Sharma, A. Chaudhary and R.V. Singh, Rasayan Journal of Chemistry, 1(1), 68(2008)

13. Z.M. Siddiqi and D. Pathania, Journal of Chromatography A, 987, 147(2003), DOI: 10.1016/S00219673(02)01659-X

14. K.G. Varshney, K Agrawal, S. Agrawal, V Saxena and A.R. Khan, Colloids and Surfaces, 29(2), 175(1988), DOI:10.1016/0166-6622(88)80115-X

15. M. Ahmadi, R. Yavari, A.Y. Faal and H. Aghayan, Journal of Radioanalytical and Nuclear Chemistry, 310(1), 177(2016), DOI: 10.1007/s10967-016-4748-y

16. R. Yavari, S. Ahmadi, Y.D. Huang, A.R. Khanchi, G. Bagheri and J.M. He, Talanta, 77(3), 1179(2009), DOI:10.1016/j.talanta.2008.08.026

17. Z. Sun and S. Tao, Lizi Jiaohuan Yu Xifu. 6, 431(1990).

18. S. Kuznicki, R.J. Madon, S. Gerald and K.A. Thrush, Eur. Pat. Appl. E.P. 405, 978, 28(1989).

19. S.K. Srivastava, S. Kumar, C.K. Jain and S. Kumar, Analyst, 109(2),151(1984), DOI:10.1039/AN9840900151

20. I. Gustian, Ghufira and D. Oktiarni, Rasayan Journal of Chemistry, 12(1), 284(2019), DOI: $10.31788 /$ RJC.2019.1215010

21. S.K. Mittal and H.K Sharma and A. Kumar, Sensors, 4(8), 125(2004), DOI: 10.3390/s40800125

22. S.K. Mittal and H.K. Sharma, Journal of Analytical Chemistry, 60, 1069(2005), DOI: 10.1007/s10809-005-0240-5

23. S.K. Mittal, H.K. Sharma and S.K.A. Kumar, Reactive and Functional Polymer, 66, 1174(2006), DOI: $10.1016 /$ j.reactfunctpolym.2006.02.008

24. H.K Sharma, A. Parmar and P. Dogra, Asian Journal of Chemistry, 29(9), 2051(2017), DOI: 10.14233/ajchem.2017.20752

25. H.K. Sharma and N. Sharma, Sensor Letters, 11(3), 1(2013), DOI: 10.1166/s1.2013.2760

26. C.N.R. Rao, Chemical Applications of Infrared Spectroscopy, Academic Press, New York, p 353 (1963), DOI: 10.1002/ange.19650770833

27. A.R. Arul, T.E. Manjulavalli, R. Venckatesh and G. Rajkumar, Rasayan Journal of Chemistry, 10(4), 1455(2017), DOI:10.7324/RJC.2017.1041927

28. G. Alberti, P. Cardini-Galli, U. Costantino and E Torracca, Original Research Article, 29, 571(1967).

[ RJC-5355/2019] 